\title{
POTENSI PENGEMBANGAN WISATA HALAL DALAM PERSPEKTIF DUKUNGAN KETERSEDIAAN RESTORAN HALAL LOKAL (NON WARALABA) DI KOTA GORONTALO
}

\author{
Krishna Anugrah ${ }^{1}$, Asminar Mokodongan ${ }^{2}$, Ade Pebriani S Pulumodoyo ${ }^{3}$ \\ Program Diploma Pariwisata Universitas Negeri Gorontalo \\ Jl. Jend Sudirman Kota Gorontalo
}

Korespondensi dengan penulis

Asminar Mokodongan: Telp: 085240428877

Email: Minang.arman@gmail.com

\begin{abstract}
This study focused on the potential development of halal tourism in the perspective support of availability of local halal restaurant (non-franchise restaurant) in Gorontalo city. In master plan of Gorontalo, Tourism Development stated that Gorontalo has potential opportunity to develop halal tourism as one of tourism destination. These potential opportunity is supported by few factors such as the majority of the population are muslims, tourist visitor are dominated by domestic tourists which also moslem. The city of Gorontalo as the capital city has many facilities than other cities in Gorontalo province such as starred hotel and non-starred hotel, franchise restaurants, local restaurants. Further, Gorontalo city has strategic position because it is located between two cities that has tourist destination and attraction. This study used descriptive qualitative method. The data obtained through field observation, interview, and documentation. All data collected by using sampling purposive technique. The obtained quantitative data will be described in descriptive terms. The completion of this research will be presented in descriptive. The results showed that the existence of a restaurant which has halal certification is sufficient to support halal tourism. In order to make it runs well, it requires cooperation among stakeholders.
\end{abstract}

Keyword: Halal; Tourism Development; Restaurant;

Gorontalo sebagai Provinsi melalui sektor pariwisata. Sektor yang baru berkembang dan terus pariwisata saat ini dijadikan salah melakukan upaya peningkatan satu program prioritas pembangunan diberbagai sektor agar tidak kalah di Provinsi Gorontalo. Potensi yang saing dengan daerah lain di dimiliki oleh Provinsi Gorontalo Indonesia, salah satunya adalah dapat dikatakan cukup banyak untuk 
dikembangkan menjadi tempat bertujuan agar pengembangan wisata, baik wisata alam maupun pariwisata mendapatkan dukungan wisata religi yang dapat menarik dari masyarakat agar tidak minat wisatawan untuk berkunjung. menimbulkan permasalahan Tempat wisata tersebut menyebar dikemudian hari dikarenakan diseluruh wilayah Kabupaten dan Kota di Provinsi Gorontalo, dengan banyaknya potensi yang dimiliki tersebut maka pilihan mengembangkan jenis wisata yang menjadi andalan juga semakin banyak sehingga dapat diharapkan menjadi ikon kepariwisataan yang diunggulkan. Salah satu pilihan pengembangan wisata yang dapat dikembangkan adalah wisata halal.

Provinsi Gorontalo memiliki Slogan Adat Bersendikan Sara, Sara Bersendikan Kibabullah, dan Kota Gorontalo memiliki slogan sebagai Kota Serambi Madinah. Kehadiran slogan tersebut sekiranya dapat membuat lebih tepat apabila kota Gorontalo mengembangkan wisata halal. Dalam upaya mendukung pengembangan wisata halal tidak hanya dilihat dari fasilitas kepariwisataan yang dimiliki namun juga harus didukung dengan struktur masyarakatnya. Hal ini dengan dianggap bertolak belakang dengan sendi kehidupan masyarakat.

Kota Gorontalo sebagai Ibukota Provinsi memiliki lebih banyak fasilitas yang mendukung dalam pengembangan wisata halal. Selain itu Kota Gorontalo juga memiliki letak yang cukup strategis karena berada diantara 2 (dua) Kabupaten yakni Kabupaten Gorontalo dan Kabupaten Bone Bolango. Kedua Kabupaten tersebut memiliki penawaran wisata yang berbeda antara satu dan yang lain bagi wisatawan yang datang untuk menikmati wisata yang tersedia. Kabupaten Bone Bolango menawarkan wisata alam sedangkan Kabupaten Gorontalo menawarkan wisata alam dan sejarah. Namun fasilitas yang diperuntukkan bagi wisatawan lebih banyak tersedia di Kota Gorontalo, sehingga wisatawan tidak mendapat kesulitan dalam menemukan kebutuhannya. 
Makanan dan minuman merupakan salah satu kebutuhan pokok hidup manusia sehingga harus dipenuhi setiap hari, kebutuhan ini tidak dapat digantikan dengan kebutuhan lain. Kebutuhan ini juga dibutuhkan oleh wisatawan, untuk mendapatkannya wisatawan dapat pergi ke rumah makan ataupun restoran baik itu yang berada jadi satu kesatuan dengan produk akomodasi maupun yang berdiri sendiri, serta warung makan yang tersedia disekitar. Dalam memenuhi kebutuhan makan dan minum bagi wisatawan ditempat yang bukan daerah tempat tinggalnya terkadang menimbulkan kekhawatiran tersendiri bagi wisatawan terutama wisatawan yang beragama islam. Hal ini dikhawatirkan karena mereka takut mendapatkan makanan dan minuman yang bertentangan dengan agama atau tidak halal, sehingga diperlukan jaminan bahwa makanan dan minuman yang dikonsumsi adalah halal.
Tabel 1. Perbandingan Jumlah Kunjungan Wisatawan ke Provinsi Gorontalo Tahun 2015 dan Tahun 2016

\begin{tabular}{|cccc|}
\hline $\begin{array}{c}\text { Jenis } \\
\text { Wisatawan }\end{array}$ & $\mathbf{2 0 1 5}$ & $\mathbf{2 0 1 6}$ & Selisih \\
\hline Domestik & 572.517 & 566.394 & $(6.123)$ \\
Mancanegara & 3.634 & 5.923 & 2.289 \\
Total & 576.151 & 572.317 & $(3.834)$ \\
\hline Sumber: BPS Provinsi Gorontalo, 2017
\end{tabular}

Pada tabel 1 dapat dilihat kunjungan wisatawan di Provinsi Gorontalo bila dibandingkan pada tahun 2015 dan 2016 mengalami penurunan secara keseluruhan, penurunan tersebut hingga mencapai 3834 wisatawan. Namun apabila dilihat dari wisatawan mancanegara mengalami kenaikan sebanyak 2.289 orang. Pangsa pasar wisatawan yang datang ke Provinsi Gorontalo masih di dominasi oleh sektor wisatawan domestik. Apabila dilihat secara jumlah maka dapat dibandingkan secara jumlah wisatawan domestik memiliki jumlah yang jauh lebih banyak daripada wisatawan mancanegara. 
Tabel 2 Persentase Jumlah Kunjungan

Wisatawan ke Kota Gorontalo dari

Provinsi Gorontalo Tahun 2015 dan Tahun 2016

\begin{tabular}{ccccc}
\hline & \multicolumn{2}{c}{2015} & \multicolumn{2}{c}{2016} \\
\cline { 2 - 5 } $\begin{array}{c}\text { Jenis } \\
\text { Wisatawan }\end{array}$ & $\begin{array}{c}\text { Jumla } \\
\mathbf{h}\end{array}$ & $\%$ & $\begin{array}{c}\text { Jumla } \\
\mathbf{h}\end{array}$ & $\%$ \\
\hline Domestik & 161.7 & 28.2 & 154.11 & 27.2 \\
Mancanega & 2.067 & 56.9 & 2.474 & 41.7 \\
$\quad$-ra & & & & \\
Total & 163.8 & 28.4 & 156.58 & 27.3 \\
\hline
\end{tabular}

Sumber: BPS Provinsi Gorontalo, 2017

Demikian halnya yang terjadi pada wisatawan ke Kota Gorontalo. Dari tahun 2015 persentase wisatawan yang datang sebanyak 28.42\%, sedangkan sisanya terbagi ke kabupaten lainnya. Pada tahun 2016 total kunjungan wisatawan mengalami penurunan $1.07 \%$ menjadi $27.35 \%$. Hal yang sama terjadi seperti kunjungan wisatawan ke Provinsi Gorontalo, wisatawan ke Kota Gorontalo juga masih didominasi oleh wisatawan domestik yang datang berkunjung. Data tersebut dapat dilihat pada tabel 2 .

Tabel 1 dan 2 menunjukkan bahwa potensi pasar wisatawan yang dimiliki Provinsi Gorontalo dan Kota Gorontalo adalah wisatawan domestik. Peluang ini harus termanfaatkan dengan sebaiknya dan dapat disikapi dengan baik sehingga dapat memberikan kontribusi kepada pendapatan daerah yang dapat digunakan untuk kemajuan daerah. Penduduk mayoritas Indonesia adalah beragama islam, maka tidak ada salahnya apabila Kota Gorontalo memprogramkan wisata halal sehingga wisatawan yang beragama islam merasakan kenyamanan dan aman dalam melakukan wisata ke Gorontalo terutama dalam hal memenuhi kebutuhan makanan dan minuman.

\section{METODE PENELITIAN}

Penelitian ini menggunakan pendekatan kualitatif. Lokasi penelitian dilakukan di Kota Gorontalo dengan melakukan teknik sampling purposive terhadap restoran lokal (non waralaba). Pengumpulan data dilakukan dengan pengamatan, wawancara dan Dokumentasi. Pengamatan dilakukan secara langsung ke beberapa restoran yang ada di Kota Gorontalo, berkaitan dengan kepemilikan sertifikat halal. Metode wawancara dilakukan kepada 
pemilik atau pengelola restoran dan juga kepada pihak pimpinan LPPOM MUI Gorontalo dalam hal pelaksanaan dan penerapan makanan dan minuman halal di restoran. Data hasil wawancara akan dipilah kembali hanya data yang diperlukan akan digunakan dalam penelitian ini. Data dokumentasi yang didapatkan dari berbagai sumber dan berkaitan dengan penelitian ini akan digunakan baik berupa data kualitatif maupun kuantitatif.

\section{HASIL DAN PEMBAHASAN}

Orang berwisata ke suatu tempat mencari sesuatu yang baru ataupun yang berbeda baik itu yang berbeda dengan yang telah ditemui atau yang dilakukan di tempat lain maupun kehidupan sehari-hari yang dijalani. Setiap daerah memiliki ciri khasnya masing-masing, dengan ciri khas masing-masing tersebut menjadi daya tarik tersendiri. Ciri khas dapat berupa budaya hingga makanan khas asli daerah. Apabila wisatawan merasa tidak cocok dalam hidangan khas daerah maka mereka juga bisa mendapatkan hidangan lain yang sekiranya disukai.

Gorontalo memiliki potensi untuk menjadi wisata halal, hal tersebut telah tertuang dalam RIPPDA Provinsi Gorontalo (2012), agar potensi tersebut dapat terlaksana maka diperlukan persiapan untuk mendukung pariwisata halal di Gorontalo, khususnya di Kota Gorontalo. Persiapan ini memerlukan waktu dan proses yang panjang, semua unsur pemegang kepentingan yang terlibat hingga fasilitas yang memadai harus mendukung bila pariwisata halal ingin terlaksana dengan baik. Penyiapan fasilitas dapat dimulai dari penyediaan kebutuhan wisatawan seperti akomodasi, makan dan minum, serta sarana transportasi.

Keberadaan jumlah restoran di Kota Gorontalo dapat dikatakan memiliki jumlah yang cukup. Dari tahun ke tahun terjadi perkembangan jumlah restoran di Kota Gorontalo, hal ini menunjukkan bahwa peluang usaha dalam bidang penyediaan makanan dan minuman masih memiliki masa depan yang cukup menjanjikan. Jumlah tersebut tersebut 
belum termasuk warung-warung yang juga menjual makanan dan minuman. Jumlah restoran yang berada di Kota Gorontalo dapat di lihat pada tabel 3. Jumlah total restoran tersebut termasuk restoran waralaba yang didirikan oleh para pemilik waralaba baik waralaba skala nasional maupun waralaba internasional.

Tabel 3 Jumlah Restoran yang Berada di Kota Gorontalo tahun 2014 - 2016

\begin{tabular}{cccc}
\hline Kecamatan & $\mathbf{2 0 1 4}$ & $\mathbf{2 0 1 5}$ & $\mathbf{2 0 1 6}$ \\
\hline Kota barat & 3 & 3 & 5 \\
Dungingi & 1 & 1 & 2 \\
Kota Selatan & 31 & 32 & 35 \\
Kota Timur & 22 & 26 & 28 \\
Hulonthalangi & 5 & 7 & 7 \\
Dumbo Raya & 5 & 6 & 6 \\
Kota Utara & 9 & 10 & 9 \\
Kota Tengah & 21 & 22 & 23 \\
Siptana & 3 & 3 & 3 \\
Jumlah & 100 & 110 & 118
\end{tabular}

\section{Sumber : BPS Kota Gorontalo, 2017}

Perkembangan restoran yang tersedia di Kota Gorontalo saat ini dapat dikatakan semakin banyak sehingga tempat yang tersedia untuk makan dan minum semakin beragam dan menu yang ditawarkan semakin beragam. Wisatawan yang datang dapat dengan leluasa memilih tempat makan dan minum yang tersedia. Ketersediaan restoran tersebut bukan hanya restoran yang menghidangkan menu makanan dan minuman khas dari Gorontalo akan tetapi juga ada restoran yang menawarkan makanan dan minuman dari daerah lain.

Mendapatkan sertifikat halal bagi sebuah usaha restoran harus melalui tahapan-tahapan yang telah ditentukan. Keseluruhan aspek juga harus dilihat dan dikaji dalam mendapatkan sertifikat halal. Aspek tersebut bukan hanya dalam hal menu yang disajikan saja akan tetapi dilihat dari proses awal. LPPOM MUI memiliki kriteria dalam pengajuan sertifikat halal, secara garis besar antara lain yakni Halal zatnya, Halal cara memperolehnya, Halal dalam prosesnya, Halal dalam penyimpanannya, Halal dalam pengedaran dan penyajiannya. 


\section{Gambar 1. Salah Satu Restoran Lokal yang Berada di Kota Gorontalo}

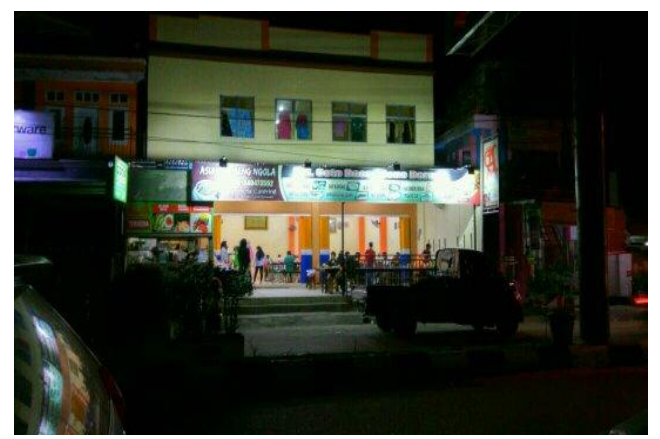

Sumber: Dokumentasi Pribadi (Ade)

Berdasarkan data pada tabel 3, dapat tergambarkan restoran yang ada di Kota Gorontalo berjumlah 118 restoran pada tahun 2016. Akan tetapi dilansir dari LPPOM MUI Provinsi Gorontalo, pada tahun 2014 restoran yang bersertifikat halal berjumlah 5 restoran, tahun 2015 bertambah menjadi 14 restoran, dan tahun 2016 bertambah mencapai 25 restoran. Jumlah tersebut sudah termasuk restoran waralaba yang berdiri di Kota Gorontalo. Merujuk pada perkembangan jumlah restoran dari tahun ke tahun, restoran yang bersertifikat halal memang bertambah, akan tetapi jumlah restoran halal diperkirakan hanya $1 / 4$ dari total jumlah restoran yang ada di Kota Gorontalo, hal ini ditegaskan oleh pernyataan wakil ketua LPPOM
MUI pada saat wawancara. Lebih lanjut dikatakan untuk restoran waralaba yang berskala nasional, sertifikat halal yang didapatkan oleh cabang diurus oleh restoran pusat perusahaan, mereka mendaftarkan cabang-cabang yang merupakan pengembangan produk restoran (outlet/dapur/gudang).

Dari jumlah keseluruhan restoran yang ada di Kota Gorontalo hanya terdapat beberapa restoran yang menawarkan menu yang merupakan ciri khas dari suatu daerah. Restoran tersebut ada yang juga menawarkan menu makanan dan minuman yang berasal dari daerah lain, seperti menu makanan makassar, menu makanan jawa, menu makanan kendari. Selain itu jumlah restoran waralaba nasional dan internasional jumlahnya juga tidak terlalu banyak. Keberadaan restoran waralaba pertama kali berdiri sejak tahun 2008 namun perkembangannya mulai tahun 2014. Perkembangan keberadaan restoran waralaba masih dirasakan sangat lambat sehingga peluang untuk mendirikan restoran lokal terutama restoran dengan menu 
ciri khas suatu daerah sangat terbuka lebar. Jumlah total restoran lokal yang memiliki sertifikat halal masih terbilang sedikit, kurang lebih sekitar 17 restoran. Hal ini dapat dikatakan masih kurang apabila dilihat dari jumlah keseluruhan restoran yang ada di Kota Gorontalo khususnya yang memiliki sertifikat halal. Namun dengan adanya jumlah sekitar 17 restoran lokal yang memiliki sertifikat halal ditambahkan dengan restoran waralaba yang juga sudah memiliki sertifikat halal sehingga berjumlah 25 restoran maka hal ini dapat dikatakan cukup menjadi rujukan ataupun pilihan bagi wisatawan yang ingin menikmati kuliner tanpa ada rasa kekhawatiran menu yang disajikan tidak halal. Hal ini dikarenakan ratarata menginap tamu menginap di Provinsi Gorontalo hanya 1,52 hari pada tahun 2016. Rata-rata menginap yang hanya 1,52 hari maka asumsinya adalah kebutuhan akan makan dan minum wisatawan yang diharus dipenuhi secara mandiri adalah sebanyak 3 (tiga) kali hingga 4 (empat) kali selama 1,52 hari. Hal tersebut diluar kebutuhan makan pagi bagi tamu yang disediakan oleh akomodasi yang mana harga kamar sudah termasuk makan pagi.

\begin{tabular}{cc}
\multicolumn{2}{c}{$\begin{array}{c}\text { Tabel } 4 \\
\text { Wisatawan } \\
\text { di Provinsi Goromtalo }\end{array}$} \\
\hline Tahun & Lama Menginap \\
\hline 2012 & 2,12 \\
2013 & 2,12 \\
2014 & 2,19 \\
2015 & 2,07 \\
2016 & 1,52 \\
\hline
\end{tabular}

Sumber: BPS Provinsi Gorontalo, 2017

Jumlah wisatawan yang datang ke Kota Gorontalo pada tahun 2016 adalah sebesar 156.585 maka dapat diasumsikan rata-rata kunjungan per hari wisatawan adalah 429 orang wisatawan yang berkunjung. Restoran lokal yang memiliki sertifikat halal rata-rata memiliki daya tampung sebanyak kurang lebih 50 kursi. Maka total kursi yang tersedia di restoran lokal yang memiliki sertifikat halal adalah sebanyak 850 kursi. Bila dibandingkan dengan kunjungan wisatawan yang datang ke Kota Gorontalo yang hany 429 orang wisatawan, maka kursi di restoran lokal yang memiliki sertifikat halal hanya terisi kurang lebih 50\% nya saja. Hal ini menunjukkan bahwa 
masih terjadi kekosongan kursi di restoran, asumsi 50\% tersebut dapat terjadi apabila semua wisatawan mendatangi restoran lokal yang memiliki sertifikat halal untuk memenuhi kebutuhan makan dan minum mereka selama berkunjung ke Kota Gorontalo. Namun apabila yang terjadi sebaliknya yakni tidak semua wisatawan datang ke restoran tersebut maka yang nampak adalah kelebihan ketersediaan kursi. Untuk mengantisipasi hal tersebut dan memajukan usaha restoran maka dapat dilakukan kerjasama dengan pihak terkait.

Keberadaan restoran yang telah bersertifikat halal dapat menjadi salah satu upaya untuk mendukung wisata halal di Kota Gorontalo. Berdasarkan pada kehidupan sehari-hari, baik masyarakat umum terlebih lagi pada wisatawan muslim, sertifikat dan logo halal pada setiap restoran masih menjadi acuan utama untuk menandakan bahwa restoran tersebut menyajikan makanan dan minuman halal. Upaya pengembangan pariwisata halal perlu didukung oleh semua pihak pemegang kepentingan.
Apabila konsep pariwisata halal ingin benar-benar diterapkan dan berjalan dengan baik maka dapat dimulai dengan mengembangkan fasilitas yang telah ada menjadi konsep halal. Pemerintah daerah sebagai penentu kebijakan harus bekerjasama dengan berbagai pihak baik itu akademisi, badan usaha yang berkaitan dengan pariwisata, LPPOM MUI, pemandu wisata, dan masyarakat.

Sosialisasi tentang perlunya keberadaan sertifikat halal pada sebuah usaha restoran harus lebih digalakkan kembali oleh pemerintah daerah dan LPPOM MUI, karena sertifikat tersebut menyatakan kehalalan, yang secara otomatis menyatakan keamanan dan kenyamanan makanan dan minuman yang disajikan kepada pengunjung restoran. Kerjasama yang erat juga harus dijalin antara penyedia jasa perjalanan wisata, usaha transportasi, restoran dan juga pemandu wisata. Kerjasama dapat berupa penawaran paket makan dan minum yang disediakan bagi wisatawan yang berkunjung ke Kota Gorontalo, yang disertakan dalam pengemasan paket 
wisata oleh operator perjalanan wisata. Penawaran paket makan dan minum juga harus dipromosikan oleh pihak restoran kepada pihak lain selain operator perjalanan wisata seperti pengemudi transportasi baik yang lokal di dalam Kota Gorontalo maupun yang menyediakan jasa transportasi antar daerah, pemandu wisata freelance, dan penyedia sarana akomodasi yang tidak memiliki restoran di dalamnya.

Upaya kerjasama tersebut selain dalam rangka memajukan usaha bersama yang memberikan pendapatan bagi masing-masing usaha, memudahkan wisatawan mendapatkan informasi keberadaan restoran lokal yang bersertifikat halal dan juga turut mendukung dan mempromosikan pariwisata halal di Kota Gorontalo sehingga pariwisata halal dapat berjalan dengan baik dan dapat dikenal lebih lagi oleh wisatawan lainnya, hal ini dikarenakan secara tidak langsung dapat dipromosikan oleh wisatawan sudah pernah berkunjung kepada kerabatnya yang belum pernah berkunjung ke Kota Gorontalo.

\section{KESIMPULAN}

Uraian penelitian di atas penulis dapat simpulkan bahwa keberadaan restoran yang memiliki sertifikat halal di Kota Gorontalo sudah dapat dikatakan cukup mendukung untuk dilaksanakannya pariwisata halal di Kota Gorontalo. Hal ini dengan pertimbangan waktu kunjungan wisatawan yang singkat yakni hanya 1,52 hari dan frekuensi pemenuhan kebutuhan makanan dan minuman wisatawan 3 hingga 4 kali saja selama 1,52 hari menginap. Selain itu rata-rata jumlah kunjungan wisatawan ke Kota Gorontalo adalah 429 orang wisatawan per hari. Sehingga bila dibandingkan dengan jumlah ketersediaan kursi di masingmasing 17 restoran maka dapat terisi $50 \%$ nya saja. Pariwisata halal agar dapat berjalan dengan baik maka diperlukan kerjasama yang baik seluruh pemegang kepentingan dalam kepariwisataan. Kerjasama yang erat antar lembaga, usaha-usaha bidang pariwisata dan juga dukungan masyarakat. 
DAFTAR RUJUKAN

Andriani, Dini dkk. 2015. Kajian Pengembangan Wisata Syariah. Diakses pada tanggal 21 Maret 2017 melalui http://www.kemenpar.go.id / userfiles/2015\%20Kajian \% 20 Pengembangan $\% 20$ Wisata $\% 20$ syariah.pdf.

Customer User Manual-Restoran, diakses pada 21 Juli 2017 dari

http:/ / www.halalmui.org/ images/stories/pdf/Manu al-CEROL-Restaurant(Indo1.2).pdf.

Hananto, Erwin. 2016.Pengertian dan Tujuan Sertifikasi Halal. Diakses pada tanggal 10 April 2017. Melalui http://www.konsultanhalal.n et/2016/05/ pengertian-dantujuan-sertifikasi-halal.html.

JATIM.LPPOMMUI. 2004. Serrifikiat Halal. Diakses pada tanggal 9 April 2017 melalui

http://halalmuijatim.org/sertifikas i/tentang-sertifikat-halal/

Lalim,Haidar Tsany 2015. Analisis Potensi Pariwisata Syariah dengan Mengoptimalkan Industri Kreatif di Jawa Tengah dan Yogyakarta.

Diakses pada tanggal 23 Maret 2017 Melalui http:/ / eprints.undip.ac.id/45 828/1/ Artikel.pdf.

Universitas Diponegoro.
Peraturan Daerah Provinsi Gorontalo No.2 Tahun 2012. Tentang Rencana Induk Pembangunan Pariwisata Daerah Provinsi Gorontalo.

Peraturan Menteri (Permen) Pariwisata dan Ekonomi Kreatif RI No.2 Tahun 2014. Tentang Pedoman Penyelenggaraan Usaha Hotel Syariah.

Prabowo. 2013. Bab III Metode Penelitian 3.7 Teknik Analisis Data. Diakses pada tanggal 12 Apriil 2017. Melalui https:/ / www.google.co.id/?g ws_rd $=$ cr\&ei $=$ gv7tWP-

ONsTmvgTMsZ74CQ\#q=tekn $\mathrm{ik}+$ analisis+data+kualitatif $+\mathrm{d}$ eskriptis.

Sugiarti, Ariqa Nurwilda 2015. Strategi Pengembengan Pariwisata Syariah untuk Meningkatkan Kunjungan Wisatawan Muslim Domestik dan Mancanegara di Kota Bandung. Diakses pada tanggal 2 April 2017 melalui http:/ / repository.upi.edu/18 281/7/S_MRL_1106074_Chap ter1.pdf

Utama, I Gusti Ray 2016. Pengantar Industri Pariwisata. CV Budi Utama. Yogyakarta.

Wiwoho, Ardjuno. 2008. Pengetahuan Tata Hidang. Erlangga. Jakarta. 


\section{BIODATA}

Krishna Anugrah

Alumnus Sekolah Tinggi Pariwisata Bali (DIV), Universitas Udayana Kajian Pariwisata (S2), Dosen Jurusan Pariwisata di Universitas Negeri Gorontalo. Email: kina_bunny@yahoo.com

Asminar Mokodongan Alumnus Sekolah Tinggi Pariwisata Internasional Jakarta
(S1), Sekolah Tinggi Pariwisata Bandung (S2),

Dosen Jurusan Pariwisata di Universitas Negeri Gorontalo. Email: Minang.arman@gmail.com

Ade Pebriani S. Pulumodoyo

Alumnus Universitas Negeri Gorontalo (DIII). Email: adevebriany182@gmail.com 